\title{
Family Teamwork and Psychotherapy
}

\author{
DANIEL R. MILLER, Ph.D. ${ }^{\mathrm{a}}$
}

JACK C. WESTMAN, M.D. ${ }^{b}$

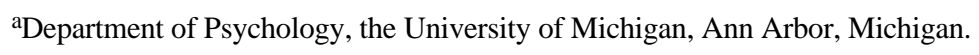

${ }^{b}$ Department of Psychiatry, The University of Wisconsin, Madison, Wisconsin. The research was supported by grant MH 01045-03 from the National Institute of Mental Health.

In clinical work as in mining the prospector who has located a rich vein devotes his initial efforts to describing the properties of the find. An increasing number of investigators, for example, have been exploring the connections between certain symptoms and mutual activities in the patients' families. Abundant evidence has been cited to show that families "need" to have the patients retain such pathologies as phobias, schizophrenic symptoms, character traits, and some forms of retarded reading, the topic of this paper.

Unlike the miner, who employs the terminology of the minerologist and the instruments developed by the engineer, the clinician lacks shared concepts and standardized instruments for exploiting his new find. Hence, although clinical accounts permit the reader to visualize with ease how the patients' problems help relatives to maintain their relationships and how families work together to resist change, there is little consensus about terms or even about the questions that are being asked. Various writers assert that they are concerned with such diverse issues as role interaction, internal dynamics, barriers to communication, collusion, compatibility, the distribution of power, and conflict between role and identity. If a researcher's findings are inherent in his questions, as many philosophers maintain, he can have little basis for organizing his efforts or interpreting the results until he is clear about his definitions and his original questions.

The object of this paper is to outline some of the primary questions and explanations about etiology and treatment that we have been developing in a study of functional retardation in reading (2). The subjects are white boys, between the ages of eleven and fifteen years, retarded at least two years in reading level, but without evidence of neurological or uncorrectable visual pathology, and at least normal in I.Q. on a nonverbal test. These subjects are outpatients at the Children's Psychiatric Hospital of the University of Michigan.

Even in our preliminary observations of retarded reading we were struck by two types of cases. In one the functionally retarded reading can be explained by poor teaching or traumatic experiences but not by familial patterns. In the other the difficulty seems to buttress relationships among family members, who have an investment in perpetuating the symptom, and, indeed, engage in activities that reinforce it. Boys in the former category, unlike those in the latter, profit from remedial teaching.

In what follows we first summarize some of the highlights of our earlier observations and some of our major concepts. We then use them to explain the roots of the symptom, its contributions to the stability of different kinds of family relationships, its maintenance by the family's teamwork, and its resistance to psychotherapy.

\section{Retarded Reading and Familial Stability}

In a previous paper (2), we postulated that the family's stability depends on the patient's identity as a "stupid boy" or "baby" or "troublemaker," and that the identity is contingent on the symptom. The parents are not able to take effective steps to improve their child's reading ability because this would change his identity and decrease family stability. Despite considerable pressure from school authorities many parents refuse psychiatric treatment or delay application for several years. When they begin psychotherapy, they tend to resist discussion of the reading problem.

Why do they come at all? They are usually prompted by a new problem, an "unofficial" one, which disrupts stability and cannot be resolved by the members. If such a difficulty is lacking, the family usually avoids help. In therapy the members are most inclined to talk about the unofficial problem and to stop coming when it is resolved.

Just how much some families require the reading problem is indicated by the disturbances that result when the child improves. Some adults deny the improvement, some sabotage the child's study, some become profoundly depressed, some show signs of psychosis, some quit therapy, some talk of divorce. As the child's reading improves, he too develops new symptoms, such as depression or antisocial behavior.

\section{The Properties of Relationships}

We trace the roots of the child's problem back to the reasons why the parents originally married each other. An understanding of these reasons requires that the marriage be viewed as a miniature social system with specific goals, 
specialized jobs performed by husband and wife, and shared values about the adequacy with which these jobs are performed. The jobs are performed to attain such goals as promoting physical security and comfort, making a living, obtaining social expression, and regulating the satisfaction of sexual needs. A few of the primary jobs in the family are: going to work, planning recreation, raising children, and homemaking.

In analyzing a marriage we begin with the partners' identities, subidentities, roles and social positions (1). The identity is the total configuration of traits that describes the kind of person one is. The self-identity is the configuration as viewed by the person himself; the objective public identity is how he is viewed by others in a particular group. The total identity is comprised of subidentities, each organized along the lines of a social role. A person's role is defined in terms of the obligations others expect him to meet because he occupies a social position such as father, husband, or factory worker. In other words a role represents the pressures of others while self-identity is one's picture of what he is like.

In line with their different roles, the husband and wife acquire social, sexual, occupational, and homemaking subidentities. When children are born the couple develop parental subidentities. In expressing a sub-identity, a spouse puts pressure, often unintentionally, on the other to assume a compatible subidentity. Compatibility describes the extent to which the combinations of partner's traits facilitate the attainment of mutual goals. A sociological term, altercasting (3), is a useful label for the pressures one exerts on others in a mutual endeavor by assuming a particular subidentity. When a man takes the initiative in sexual relations, he is altercasting a passive sexual subidentity for his wife; when she projects her hostility to a mutual friend whom she then shuns, she is altercasting a suspicious and rejecting social subidentity for her husband. Each spouse's actions are therefore of great consequence to both, and an understanding of the behavior of either requires information about the underlying dynamics of both.

Just how comfortable each spouse feels with the other's role pressures and altercasting depends on the compatibility between certain traits of his subidentity and the requirements - ultimately the subidentity—of the partner. With experience each learns how to split every subidentity into presented and private parts in a manner that achieves his ends by hostile demands to which his wife defers; privately he may be a guilt-ridden Milquetoast who submits to her sadistic dominance. When two people split their subidentities in compatible ways they can perform both their presented and private tasks with relative comfort. The degree of compatibility is one component of stability, a property of a marital system that causes it, when equilibrium is diminished, to restore equilibrium and maintain the basic characteristics of the relationship. The longer the average couple lives together and works toward the same goals the more successful they become in thinking, feeling, and acting together in coordinated ways. The mutual altercasting provides the pattern of the couple's coordinated activities; this we call teamwork.

\section{Roots of the Symptom}

What has been described thus far applies to all relationships, normal and pathological. Parents of children retarded in reading betray socially handicapping flaws in various subidentities. Some partners have strong predilections for aggressive outbursts followed by strong guilt. Some act like helpless children lost in the world of adults. Some display a reversal in their sexual subidentities, the masculine looking men having covert infantile tendencies, and the feminine looking women having covert phallic and sadistic tendencies. Such dispositions can usually be traced back to childhood.

Paradoxically, despite the pathology, these marriages are strikingly stable. The average husband and wife split themselves in such a manner as to create good fits between their presented identities, between their private ones, between their conscious ones, and between their unconscious identities. The man who is effeminate in private has usually found his way to the doorstep of a woman who is privately masculine. More often than not, his presented masculine identity is safeguarded by her outwardly feminine behavior.

Similarly a man prone to infantile, aggressive outbursts followed by strong guilt has often had surprising success in finding a woman who is pleased to provoke his aggression and to gratify his need for punishment. The childish man has found a childish wife who shares his predilections for projecting his unconscious, aggressive subidentity to hostile outsiders and for seeking refuge in a private castle where he can nurse his fantasies.

Though bonds between pathological traits bolster stability, they create marked fluctuations in equilibrium and a gradual diminution of stability. Contributing to the instability are the marked discrepancies between each partner's roles and subidentities. For example, people outside the family expect the effeminate husband to show masculine initiative on his job and in the marriage. He consequently finds it increasingly difficult to spend time with outsiders because they do not blind themselves to the private parts of his identity, and their reactions help him to see himself in the way that they see him.

Even a severely curtailed social life, however, does not prevent the world from intruding on the marriage; the husband goes to work, the wife makes purchases, both see some friends or relatives, both go to church. When other people's evaluations cannot be avoided, one can repress the unacceptable, private parts of one's subidentity or one can distort the public's evaluation by denial or by projection of one's own hostility or ineptitude. These defenses enable the couple to avoid the anxiety created by the conscious acknowledgement of illicit bonds, but only at a painful cost. Outsiders are seen as 
increasingly persecuting, and the barrier between the marriage and the external world becomes progressively impermeable.

Social isolation cannot completely eliminate the sources of instability because each spouse has internalized a part of the external world. Independent of the expectations of outsiders, each person evaluates his subidenties in terms of society's standards, so that each is guilty or ashamed of some of his own private behavior and that of the spouse. Such internalizations explain why a wife consciously deplores her husband's passivity even though she promotes it.

In addition to creating anxiety, illicit subidenties create practical social handicaps. Passivity makes it hard for a man to earn a living; excessive projection can create unrealistic resentment of others; retreat into infantile fantasy makes a man unproductive.

The marriages based predominantly on illicit, private bonds face even further sources of instability. With the passage of time, the couple's parents die, children are born, the wife gives up her job and stays home. Upon the death of his mother and the birth of his own child, the passive man experiences new pressures to change from being someone's son to being someone's father. These pressures create increased discrepancies between the public and private parts of the marriage. In time, too, some couples outgrow childish subidentities. When these are the primary sources of bonds, the husband and wife may discover one day that they are strangers to one another.

If the relationship survives, the average couple gradually becomes adept at adjusting to the contradictions of presented and private relationships. A father becomes skilled at taking the lead at work and being passive at home; the mother at behaving like a demure female in public and a dominant organizer in private. Depending on the changing intensities of the public's role pressures and the spouses' defenses, the average family experiences considerable fluctuations in equilibrium. Stability diminishes when the unconsciously passive man denies his feminine subidentity by becoming brutally masculine and creating resentment in his wife, and when the dominant wife expresses her contempt of her husband in public. Stability is enhanced when the couple can express their private subidentities in the absence of public exposure.

\section{The Child as Stabilizer}

The birth of a child tips the balance toward instability because his presence requires the development of new subidentities in parents and siblings. If the marriage is a disturbed one, the couple's limited resources may preclude the development of adequate parental subidentities. Instead of modifying themselves so as to fulfill the child's needs, the parents mold him to fit their relationship. If he conforms he helps to even the bumpy road traversed by the marriage. By developing a required subidentity he can support his parents' splitting of themselves in a manner that maximizes compatibility. Consider the instance of the father whose role pressures were making it increasingly difficult for him to maintain the split between his presented occupational subidentity, which was dominant and competent, and his private one, which was passive and incompetent. Projecting the unwelcome, private part of himself to his son made it easier for him to remain aware only of his public subidentity; the son internalized this as part of his own presented subidentity as inept student. The boy's acceptance of the projection led him to perform poorly in school and enabled his mother to express her private, dominant subidentity by coaching him with homework.

In one family the presence of an amenable child helped to smooth out a marital relationship in which a dominant man denied his private passivity by becoming increasingly brutal to his wife. Although her private dominance was compatible with his private passivity, this bond did not provide her with enough consolation to outweigh her many frustrations. She finally obtained revenge. She covertly encouraged her son to goad his father in ways which permitted no retaliation. The boy would express an interest in learning a sport like fly-casting or hockey, in both of which the father was an expert, and then drive him frantic by demonstrating excessive ineptitude. By identifying with her son, the mother participated vicariously in the frustration of her husband.

Another long-suffering wife obtained relief from her husband's attacks by diverting them to the boy. She kept confiding her worry about his poor grades to her husband, knowing that he would become punitive. Usually he curtailed the boy's social life and eliminated his weekly allowance until his grades improved. When the father laid down the law, the mother secretly permitted her son to see his friends during the day and gave him his allowance. In time she became the fulcrum around which father and son expressed their mutual antagonism.

One couple who were unable to control their attacks on each other began to displace their rages to their son, who accepted the identity of troublemaker. By serving as a scapegoat, he diverted parental aggression when it reached a dangerous threshold. He was prompted to do this because the attacks and the ensuing guilt-ridden bribes constituted his primary sources of attention. The strife and the bribery were so preferable to being ignored that he frequently provoked the parents' attacks.

Children provided new bonds for a couple whose marriage was characterized by minimal communication and a barren sexuality, offering relief to the father's anxiety about castration and to the mother's anxiety about her penis envy and sadism. When they become parents, each developed a "romance" with a child of the opposite sex. In addition to becoming a safe heterosexual object to his mother, the boy, who was the patient, was also a homosexual object to his father. His subidentity 
as a helpless baby, which was bolstered by his poor performance in school, permitted sexualized relationships with both parents.

\section{Flexibility and the Status Quo}

Although the families of children with reading difficulties tend to be stable, they are typically inflexible. Flexibility refers to the adaptability of the family as a system to changes in the sources of stability. A change may be induced by extreme stress, such as disabling illness. More typically the family is entering a new phase of development: a baby is born, a child enters school, an adolescent leaves home, the husband retires. Because its aim is change, psychotherapy demands flexibility. The families we have observed find it difficult to alter their basic patterns of relationships to adjust to new conditions. As noted earlier, the parents are already handicapped by limited means for solving personal problems. Hence the child has had to adapt himself to the parents, not the parents to the child.

As one means of assessing flexibility we ask each family to take a test requiring the making of group decisions. On each trial they decide together which of six buttons on a machine is the correct one to press and who is to do the pressing. The answers to problems are arranged in series of six, an example of which might be 1-1-2-2-3-3. When the correct button is pressed a bell rings; when the wrong button is pressed a buzzer sounds.

In the average family with a retarded reader, the parents speak warmly to the son and encourage him to press the button when a choice has been made, but they avoid asking him to make guesses and ignore those choices that are proferred or patiently explain why they are wrong. After the initial trial period, one parent is usually most influential in the choice of numbers. To see if the family can change its pattern of decision-making, we then manipulate the results so that this most influential person is wrong whenever the family follows his suggestions. In a pilot study, none of 15 families with retarded readers changed their procedures. Most of their members later expressed unawareness of the deterioration in the performance of the opinion leader. In contrast, almost a third of 15 normal families recognized that something had gone wrong and began to follow someone else's lead.

To create another kind of stress we later make everyone's estimate wrong for a period of trials. The continuing failure usually elicits evidence of private, collusive bonds, and the teamwork the family uses in emergencies. When one family suffered a sequence of ten failures, for example, the implacable father insisted on trying buttons one to six, in turn, on every trial. In another family the son, who had been pressing the buttons, pulled his chair away from the machine as if by prearrangement and was replaced by his impatient father, who had been accusing the boy of pressing the wrong buttons. The father then kept looking back to the mother who told him which buttons to press without giving reasons. Even when most of her answers were wrong, no one suggested that anyone else participate in the decisions.

Handicapped by inflexibility, the typical family in our sample is inclined to deny the reading problem, to avoid therapy when in difficulty, to seek help only when plagued by another problem, to stop therapy when the private problem is resolved, and to become very upset when the severity of the symptom diminishes. When flexibility is low, it is the status quo that signifies stability; change signifies instability.

\section{Teamwork}

During psychotherapy, a family often acts like a well-drilled team. At times, when interviewed together, they all feel persecuted, or they all become confused, or they all find it hard to think of anything to say, or they all are preoccupied with and silent about the same secret, or they all agree on a fabricated version of a touchy incident, or they all start arguing with one another and then blame the therapist for upsetting them. When individuals are seen separately they often confer afterwards, each person reporting on what happened during his hour.

Families typically employ teamwork for five different purposes, usually private and unconscious. The most general goal, which also enters into the other four, is maintaining the status quo, particularly with respect to the child's subidentity. One couple nagged their adolescent son into being a "good boy." To qualify he had to be passive, compliant, infantile and sexless. When he rebelled, his mother histrionically took to bed with intense heart pains, presumably induced by the son, and the father expressed the horror of one who had sired a homicidal son.

A second, and more specific aim of teamwork is to maintain the symptom. The average family with a retarded reader convinced their son that he was doing as well as might be expected in view of his presumed limitation in intelligence. They denied clinical reports that his intelligence was normal, or disparaged the validity of the tests. Some mothers coached their sons in reading after being told that the boring drills would kill their son's budding motivation to learn. Some parents set such high standards that their sons were bound to think they failed no matter how well they performed. Some parents were so punitive when their sons got poor grades that the boys retaliated by failing even more.

A third aim of teamwork is to maintain the acceptability of the family's presented identity. In the initial interview we were often greeted by a cheerful, cooperative, "all-American" family whose members were striving to attain their ideal of "togetherness" and were sure that they had no problems apart from the boy's retardation in reading. This presented identity 
usually changed markedly after a few visits.

Fourth, teamwork protects the family's secrets. In therapeutic interviews, when one member of the family began to talk about the skeleton in the closet, the others started conversations on unrelated subjects. If he persisted, they continued to divert the discussion to peripheral topics or tried to talk him out of his opinion.

A fifth aim is eliminating a threat to stability. One of the more extreme threats is an improvement in the child's reading. When this occurred the members of many families drew up ranks around a common program. They missed appointments and offered carefully reasoned excuses; they projected unconscious parts of subidentities to the therapists, and accused them of using ineffectual methods or of persecution; they punished the boys for other faults and seemed indifferent to the improvement; they even changed their hours of work or their jobs, which meant a cessation of psychotherapy.

\section{Conclusions}

The terms "husband," "wife," and "son" refer to social positions with commonly understood privileges and obligations to carry out some of the family's work. In occupying his social position, each member develops unique subidentities, which are the patterns of traits in terms of which he sees himsef (self-identity) and others see him (objective public identity). When a member expresses a subidentity he is altercasting, or setting limits, on his partner's subidentity. The adjustment of people to one another may be analyzed in terms of two kinds of compatibility: between each member's subidentities and his role pressures, and between his subidentities and those of the other members.

We postulate that in the family with a child who is retarded in reading, the husband and wife have been emotionally handicapped from childhood. To resolve some of the salient problems of the marriage they have taken recourse to private, illicit bonds which violate role pressures and create discrepancies between presented and public relationships. The marriage tends to be inflexible because resources are limited and many bonds, being private and unconscious, are not subject to rational consideration. It is necessary, therefore, for the parents to mold the child to their relationship instead of changing their identities in a manner that meets the needs of all three. Because there are few or no alternatives to the family's current style of doing its work, its members usually resist change in therapy by means of elaborate methods of teamwork.

Obviously this account is pertinent only when familial stability is contingent on subidentities of which the symptom is an essential ingredient; in the intellectually ambitious family that requires a scapegoat, for example, and where the son's failure in school work helps him to assume the required subidentity of troublemaker. When the stability is not contingent on the son's subidentity of which the symptom is a part, he can profit from remedial lessons and need not be expected to resist change. When the family does resist change in a child's pathological subidentity the symptom is refractory to treatment. In some instances the child may improve his reading at the cost of breaking up the family or inducing psychosis in a parent. This confronts the clinician with a choice between safeguarding the family's integrity and protecting the child's future. In some cases we can help the parents to maintain salient bonds and still alter relationships sufficiently to give the child freedom to develop his intellectual potential. Employing the concepts and principles described in this paper provides a framework for understanding the family's dynamics and setting realistic goals in psychotherapy.

\section{REFERENCES}

1. Miller, D. R., (1963) "The Study of Social Relationships: Situation, Identity and Social Interaction," in Koch, S. (Ed.), Psychology: A Study of a Science, Vol. 5, New York, McGraw-Hill.

2. Miller, D. R. and Westman, J. C., (1964) "Reading Disability as a Condition of Family Stability," Fam. Proc., 3, 66-76.

3. Weinstein, E. A. and Deutschberger, P., (1963) "Some Dimensions of Altercasting," Sociometry, 26, 454-466. 